\title{
DIFERENTES ABORDAGENS DA METODOLOGIA CANVAS: UMA ANÁLISE COMPARATIVA PARA A CONTRIBUIÇÃO NO DESENVOLVIMENTO DE NEGÓCIOS
}

\author{
Fernando Buzzi Gonçalves de Jesus ${ }^{1}$ \\ Eliane Gariani ${ }^{2}$
}

RESUMO: Empreendedorismo, inovação planejamento estratégico, marketing, são o carro chefe para a criação e administração de qualquer empresa ou projeto. Para tanto, neste artigo descreve-se como que essa estrutura pode ser compreendida, através de ferramentas que facilitam a visualização do negócio e, portanto, viabilizam decisões mais assertivas para um projeto de empreendimento. São apresentadas duas ferramentas utilizada para a estruturação de um negócio, o Business Model Canvas e o Brain Model Cavas, aplicadas na formatação de um projeto de treinamento para lideranças. Com a utilização destes instrumentos, fica evidente de contribuição do Brain Model Canvas para identificar e melhor conhecer o potencial consumidor, já o Business Model Canvas para a estruturação da proposta de valor do negócio como um tudo.

Palavras-chaves: Empreendedorismo. Planejamento estratégico. Planejamento estratégico em marketing. Inovação. Business Model Canvas. Brain Model Cavas.

\section{INTRODUÇÃO}

Existem várias ideias de novos negócios em que as pessoas se empenham para aplicar, porém após a (boa) ideia, um passo, por vezes, difícil de ser dado, é a estruturação do novo negócio. Como se faz, de onde se parte, quais as bases que devo considerar, e como ser objetivo ao mesmo tempo? Quais os desafios que o mercado apresenta? Como transformar a ideia em algo concreto? Como, por exemplo, uma proposta de prestação de serviço de formação em liderança, onde temos um mercado abarrotado de ofertas e ao mesmo tempo necessitado. Como chegar no consumidor e mostrar seu diferencial?

Para facilitar o desenvolvimento de novos negócios ou mesmo melhoria de negócios já disponíveis no mercado, há diversas ferramentas de planejamento, cada uma com sua

\footnotetext{
${ }^{\mathrm{I}}$ Psicólogo, especialista em Neuropsicopedagogia e educação especial inclusiva. E-mail: fernando.buzzi@hotmail.com

${ }^{2}$ Orientadora do artigo. Professora na Univille. Mestre em Administração pela PUC-PR. E-mail: eliane.gariani@yahoo.com.br.
} 
especificidade e aplicabilidade. Este trabalho se propõe a analisar as ferramentas de estruturação de negócios Business Model Canvas e Brain Model Canvas, a partir de aplicações em um programa de treinamento para líderes, o que proporcionará explorar a possibilidade de lançamento desta ideia de negócio no mercado.

Foram selecionadas estas duas ferramentas porque o Business Model Canvas permite uma visão ampla do negócio, enquanto o Brain Model Canvas orienta para uma melhor compreensão sobre a relação entre o produto ou serviço ofertado e seus respectivos consumidores.

Desenvolveremos sobre o questionamento que norteia nossa pesquisa, que se refere a quais as diferenças e contribuições práticas que as ferramentas de estruturação de negócio possuem.

A metodologia que adotamos de pesquisa é qualitativa, composta por revisão bibliográfica e estudo de caso da aplicação de duas variações do método Canvas em uma ideia de negócio de treinamento de líderes.

O artigo aborda empreendedorismo, para compreender o contexto de utilização das ferramentas e ao público que ela objetiva servir, inovação nos negócios, para a compreensão da utilização das duas abordagens do Canvas como algo contínuo no negócio, planejamento estratégico, que se utiliza diretamente das ferramentas e encerra-se com a análise de utilização delas.

\section{METODOLOGIA}

A presente pesquisa apresenta uma abordagem qualitativa, composta por revisão bibliográfica e estudo de caso da aplicação de duas variações do método Canvas em uma ideia de negócio de treinamento de líderes. Para alcançar o objetivo proposto, foram levantados dados qualitativos e submetidos a análise pela revisão teórica que o pesquisador trouxe sobre o tema referido.

A obtenção de dados foi feita através da aplicação das variações do método Canvas na ideia de negócio de formação de líderes que o pesquisador tem.

A partir da análise comparativa das duas variações do método Canvas, foram apresentados os elementos que melhor se adequam ao tipo de negócio utilizado no estudo de caso. 


\section{FUNDAMENTAÇÃO TEÓRICA \\ 3.I Empreendedorismo}

Para conceituar empreendedorismo, buscamos no site oficial do Sebrae-SC, onde Bueno (2019) que trouxe a definição:

Empreendedorismo é a capacidade que uma pessoa tem de identificar problemas e oportunidades, desenvolver soluções e investir recursos na criação de algo positivo para a sociedade. Pode ser um negócio, um projeto ou mesmo um movimento que gere mudanças reais e impacto no cotidiano das pessoas.

Sendo assim, toda ação de executar algo novo, que seja benéfico ao meio, é uma forma de empreender, gerando rendimentos de qualquer espécie ou forma.

Para a Endeavor (2020): “Empreendedorismo é a disposição para identificar problemas e oportunidades e investir recursos e competências na criação de um negócio, projeto ou movimento que seja capaz de alavancar mudanças e gerar um impacto positivo".

O empreendedorismo está diretamente ligado a visão do empreendedor (aquele que empreende). Esta visão é interligada com o comprometimento de inovação do negócio/projeto.

Aquele que empreende é chamado de empreendedor e aqui colocaremos o perfil desta pessoa, segundo Bedê (2016): “Um empreendedor é um realizador que coloca em prática novas ideias, por meio de criatividade. Isso muitas vezes significa mudar tudo o que já existe".

No Brasil o índice de empresas que fecham em pouco tempo de vida é altíssimo, se comparados a outros países mais desenvolvidos. Segundo Bedê (2016), 23,4\% das empresas abertas entre 2008 a 2012 no Brasil, fecham em dois anos. Este pode ser um indício de falta de planejamento adequado para o negócio.

\subsection{Planejamento Estratégico}

Buscamos compreender o que é um planejamento estratégico e autores como Andion e Fava (2002, p.27,) nos auxiliam:

O planejamento estratégico é um importante instrumento de gestão para as organizações na atualidade [...] tendo como objetivo fornecer aos gestores e suas equipes uma ferramenta que os municie de informações para a tomada de decisão, ajudando-os a atuar de forma pró ativa, antecipando-se às mudanças que ocorrem no mercado em que atuam. 
Planejamento estratégico é fundamental para estruturar modelos de negócios, definindo elementos como o público a que se deseja alcançar. Com a base bem estruturada, podemos tornar o negócio mais pronto para a venda e minimizar as chances de fechamento, para, desta forma, não fazer parte da estatística trazida por Bedê (2016) no tópico anterior.

Segundo Drucker "planejamento estratégico é um processo contínuo e sistemático de tomada de decisões que envolvem riscos controlados, ao se conhecer o possível futuro contido, medição de resultados obtidos em confronto com os esperados e controle das atividades viabilizadoras" (DRUCKER apud BRITO e FURTADO, 2016, p.3). Temos o planejamento estratégico como uma ferramenta que nos permite mensurar a amplitude do negócio, suas possibilidades e riscos envolvidos, para dar base e sustentação futura, o que envolve revisitar tal planejamento constantemente, a fim de mantê-lo vigente.

Brito e Furtado (2016) dão indícios de como começar a executar um planejamento estratégico, por meio de três etapas: "primeiro: O que este negócio realiza, o que ele faz ou oferece? Identifica as estratégias e suas finalidades; segundo: $\mathrm{O}$ que acontece no mercado que está inserida? Visando seus pontos fortes e fracos; e terceiro: O que deve-se fazer a partir dessas informações?”.

Estes questionamentos dão o direcionamento para a condução do negócio. Após termos propriedade sobre as respostas, podemos iniciar as pesquisas que serão necessárias para a criação da estruturação do planejamento estratégico, que é um mapeamento do negócio, dos clientes e das possibilidades que envolvam o negócio, tai como a missão, a visão e o objetivo da estratégia da empresa.

\subsection{Planejamento Estratégico de Marketing}

Quando juntamos os temas de planejamento estratégico com marketing, adentramos uma das áreas do negócio que está diretamente ligado ao cliente, em como acessá-lo. Para este conteúdo Seitz presta-nos seu conceito sobre o tema: "poderão contribuir para o aperfeiçoamento das propostas de plano de negócios, reforçando seus vínculos com seus respectivos mercados, arena final do embate que premiará os vencedores com sua conquista e fidelização" (2005, p.92). 
O marketing do produto ou serviço será realizado durante a estruturação do negócio, começando a pensar as formas de acesso ao cliente. Portanto, como divulgar e a quem o fazer são uma de suas necessidades, para evitar trabalhos desnecessários e procurar ser mais assertivo na relação marca-consumidor.

O marketing, juntamente com o planeamento estratégico, possibilitará pensarmos a forma que o cliente enxerga o negócio, e quais os benefícios que ele obterá na compra do produto ou serviço, mas, para isso, deve-se investigar muito bem a necessidade existente no cliente. Se ela não é explícita, deve-se pensar de que forma clarificar a necessidade do cliente.

Sendo assim, o planejamento estratégico tem um foco maior na gestão da empresa, o planejamento do negócio em si, enquanto o marketing dará mais luz na relação que se pretende estabelecer com o cliente. Saber como o cliente percebe a empresa, a fim de entregar mais que uma satisfação utilitária para ele e sim transformar esta relação numa paixão pela marca.

\subsection{Inovação nos Negócios}

A inovação, segundo Fonseca e Faria (2014, p.374), "trata-se de um construto complexo, com diferentes concepções, dimensões e contextos de aplicação que, por consequência, é compreendido sob diferentes abordagens teóricas em vários campos do conhecimento, ramos de atividade e setores industriais".

$\mathrm{Na}$ fusão destes conceitos, podemos entender que diante da obtenção de uma estratégia que seja mais adequada a nosso segmento, e visando o cliente como o principal fator de nossos negócios, podemos assim ter um resultado mais assertivo.

Para a obtenção da inovação, o mercado dispõe de uma série de ferramentas. Nos últimos tempos o Design Thinking tem sido uma das mais aplicadas. Trata-se de uma ferramenta para a obtenção de ideias de novos negócios ou mesmo de melhoria de negócios já existentes. A partir dela, simplificou-se o processo de inovação, além de reforçar a necessidade de inovar que todos os negócios têm.

O autor Vianna, (2012, p. 13) diz que "o design como disciplina tem por objetivo máximo promover bem-estar na vida das pessoas”. Quando pensamos em vender algum 
produto ao consumidor, devemos pensar em seu bem estar também. Isso o fará ter interesse em adquirir o produto oferecido.

\subsection{Business Model Canvas}

O Business Model Canvas é uma ferramenta de criação ou melhoria de negócios. Ela tem a finalidade de compreender quais são as melhores formas de estruturar um empreendimento.

O inventor desta ferramenta é Alexander Osterwalder. Segundo a página Startupi:

Ele é suíço e viajou o mundo para afinar com mais de 400 empreendedores a ferramenta que ele consolidou: o Canvas do modelo de negócio, explicado no livro Business Model Generation. A metodologia vem sendo adotada mundo afora e figura entre as mais recentes e profundas inovações no que diz respeito a como abordar novos produtos e negócios.

Brito e Furtado (2016, p.4) dizem que o Canvas "é uma ferramenta que possibilita uma leitura unificada sobre modelos de negócio abordando quatro áreas principais de qualquer negócio: Cliente; Oferta; Infraestrutura e Viabilidade Financeira”.

De forma resumida, o Canvas funciona da seguinte maneira:

No livro, Osterwalder e Pigneur introduzem uma ferramenta facilitadora denominada $\mathrm{O}$ Quadro, em que dividem as principais áreas de um negócio (clientes/usuários, produtos/serviços, infraestrutura e viabilidade econômica/financeira) em nove componentes: Proposta de Valor, Segmento de clientes, Canais, Relacionamento com Clientes, Fontes de Receitas, Recursos principais, Atividades principais, Parcerias Principais e Estrutura de Custos. Cada um dos nove blocos envolve uma ou mais áreas da empresa, facilitando, de uma forma visual, enxergar as relações entre os blocos e, consequentemente, a atuação de cada um deles visando à entrega de valor para o cliente (Enachev e Kaminski, 2014 p.3).

\section{Quadro I}

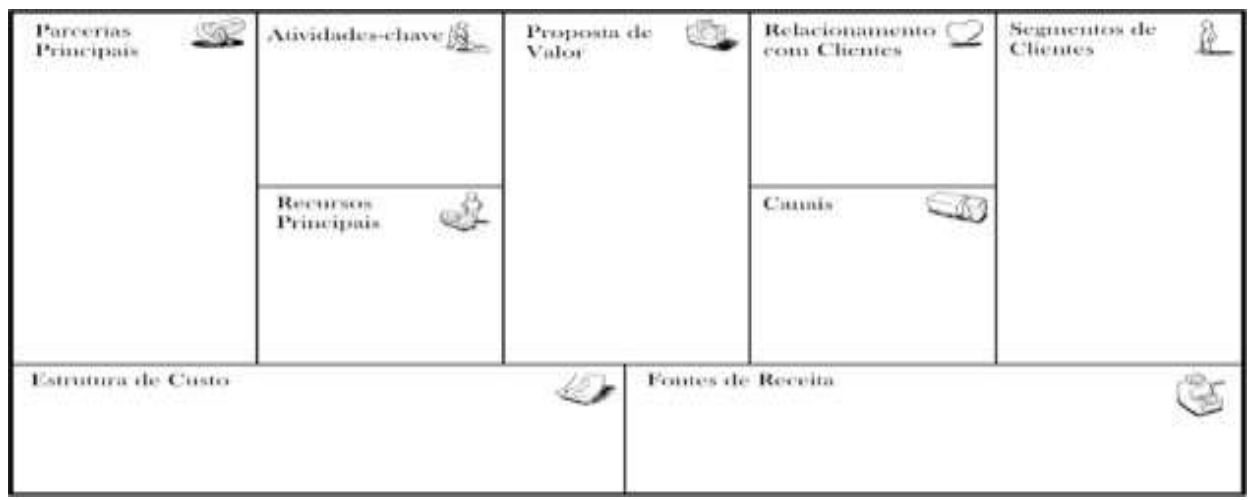

Fonte: Dicionário Financeiro (2019). 
A ordem de preenchimento dos quadrantes segue uma lógica de eficácia e de sustentabilidade para o negócio. Primeiro o segmento do cliente, identificando assim quais os interesses e necessidades do cliente. Depois a proposta de valor, seguida pelos canais e relacionamento estabelecido com o cliente, averigua todas as possibilidades de fontes de receita, passando para os parceiros principais que possui no processo as atividades chave a ser desenvolvida, os recursos principais necessários e finalmente a estrutura de custos.

\subsection{Brain Model Canvas}

O Brain Model Canvas é uma variação do Business Model Canvas. Esta ferramenta busca identificar quem é o consumidor e como este percebe o produto ou serviço a sua disposição. Inicialmente sua aplicabilidade foi proposta para a compreensão deste relacionamento marca-consumidor em redes sociais, mas pode ser expandido para outros ambientes. Segundo Biava (2017, p.51):

Esse é o primeiro modelo neurocientífico do Brasil para gestão dos estados emocionais de usuários de redes sociais, seu foco está direcionado a todos os empreendedores digitais que almejam resultados com maior eficiência e retorno em seus negócios por meio do uso das redes sociais como uma ferramenta de vendas e relacionamento. É um modelo mental de concepção de ideias composto por onze blocos que ao serem preenchidos e analisados geram conexões ente cada bloco e estratégia por meio da aplicação neuromarketing.

\section{Quadro 2}

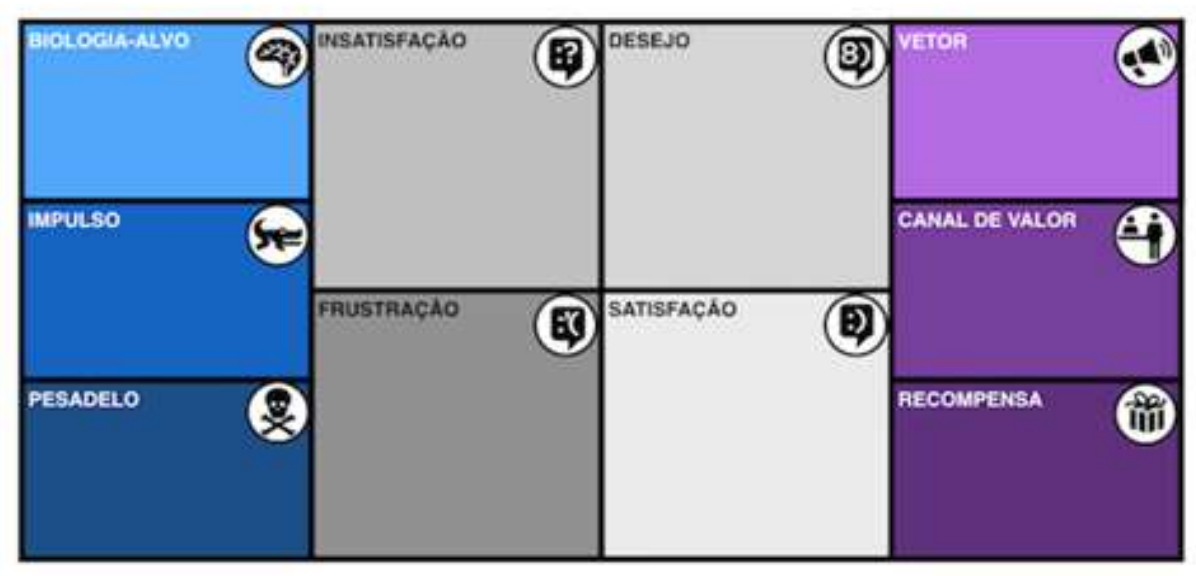

\section{BMCACTIONPLANNING}

Fonte: Marcelo Peruzzo (2019). 
Para esta tabela, existe um olhar principal que é o cliente, o preenchimento se dá de fora para dentro, identificando assim as ações principais que devem ser tomadas no amago do negócio.

\section{CASO}

\section{I Aplicação do Business Model Canvas}

A ferramenta Business Model Canvas foi aplicada na ideia de negócio de fornecer um serviço de formação de líderes, conforme descrição sintetizada abaixo, que se encontra na ordem solicitada pelo instrumento.

\section{(I) SEGMENTOS DE CLIENTES}

$\checkmark \quad$ Líderes/gestores de pessoas e aspirantes a gestão

Este serviço objetiva fornecer aos líderes/gestores de pessoas, e aspirantes a gestão, uma forma mais eficaz de trabalhar com pessoas. Os resultados dos trabalhos se darão por intermédio da qualidade da relação que o gestor estabelece com o grupo e a facilitação da relação entre os membros do grupo. Portanto, o público almejado são pessoas que estejam em processo de qualificação de sua forma de gerir.

Tendo em vista que a produção, ou o resultado do serviço, em quantidade e ou qualidade são prioridade no mundo coorporativo, a real consciência do papel de um gestor será (por vezes) muito mais importante do que a forma em que o grupo se encontra. Gestor é um agente de relações humanas. Se este conceito não estiver claro a quem se propõe estar à frente de uma equipe, possivelmente os resultados não serão os almejados, pelo menos não sem uma grande dose de estresse. Fator este que poderia ser amenizado com uma ótima gestão e, em segundo plano, o conhecimento técnico necessário.

\section{(2) PROPOSTA DE VALOR}

A proposta de valor do produto que estamos oferecendo ao nosso cliente é a melhora em sua capacidade de gerir pessoas, de estar em grupo e de facilitar a relação do grupo afim de alcançar os resultados esperados, através do método Líder Servidor com uma visão humanista Rogeriana. Esta pessoa irá poder vivenciar um conteúdo que propicie uma ampliação de consciência de sí e do grupo. Algo que distingue de outras 
formações, pois a ampliação de consciência é diferente do que adotar uma filosofia, é poder identificar, modificar e adequar a própria filosofia de cada grupo.

\section{(3) CANAIS}

O serviço será entregue no molde de formação de conhecimento intelectual e vivencial para que o participante obtenha o conhecimento e possa começar a treinar suas habilidades no grupo de uma forma mais consciente.

Para isso, serão coordenados encontros imersivos, em locais distintos, mas que propiciem tal mergulho do participante nos desafios da liderança.

\section{(4) RELACIONAMENTO COM CLIENTES}

$\checkmark$ Redes sociais

$\checkmark$ Parceria com empresas

$\checkmark$ Associação comercial

$\checkmark$ Site de inscrição

Vários são os meios que podemos entrar em contato com pessoas interessadas, as

mídias sociais hoje são nossas principais ferramentas. Realizando todo um trabalho de criação de materiais para a divulgação, podemos chegar mais próximo do público que deseja tal formação. E, claro, com contatos diretos a associações organizacionais.

Auxílio no desenvolvimento pessoal em liderança Servidora através da convivência entre o grupo. Contínua consultoria.

$\checkmark$ O acompanhamento se dará por contatos realizados tanto dos formadores quanto dos formandos.

Como a proposta é auxílio á gestores exercerem a gestão de uma forma mais próxima do ideal, trazemos em nosso método, com auxílio da teoria Rogeriana, uma forma mais pessoal de lidar com as pessoas, como diria Rogers: Mais autêntica. Não no sentido de falar o que vem à mente, mas em compreender seus próprios sentimentos e auxiliar a equipe a compreender o próprio sentimento ou sentido que estão dando a tarefa ou a execução da mesma e o papel de cada um, e do grupo como o diferencial neste trabalho. 


\section{(5) FONTES DE RECEITA}

A fonte de receita se dá pela venda de inscrição do programa de formação de líderes, estes poderão ser vendidos no valor à vista, ou mesmo em parcelas. Há também a possibilidade da venda de livros do idealizador do programa no local do evento, que permeiam ou colaboram para a compreensão dos assuntos do workshop.

\section{(6) RECURSOS PRINCIPAIS}

$\checkmark$ Conhecimento do conteúdo

$\checkmark$ Método

$\checkmark$ Livros,

$\checkmark$ Materiais de comunicação

$\checkmark$ Outros materiais tecnológicos que houver.

E principalmente a vivência de cada integrante.

Com a continuidade das formações e ampliação do negócio, há a possibilidade de realizar treinamentos com alguns profissionais, que já tenham uma certa formação e aptidão para este formato de workshop, para que possam não só auxiliar, conduzindo grupos de formação de líderes, ampliando assim a capilaridade do negócio.

\section{(7) ATIVIDADES-CHAVE}

$\checkmark$ Marketing em mídias sociais e parceiros

$\checkmark$ Preparação do local do evento

Aqui engloba-se todas as atividades realizadas pelo formador e ou equipe de formação.

(8) PARCERIAS PRINCIPAIS

$\checkmark$ Empresas

$\checkmark$ Associações organizacionais

As divulgações serão feitas através de parceiros que tenham interesse em ajudar seus gestores. 


\section{(9) ESTRUTURA DE CUSTO}

$\checkmark$ Local e estrutura do evento

$\checkmark$ Comunicação para a venda do serviço

Toda realização de eventos possuí custos, estes custos devem ser mensurados para que o evento seja viável aos participantes e rentável aos formadores.

\subsection{Aplicação do Brain Model Canvas}

A ferramenta Brain Model Canvas foi aplicada na ideia de negócio de fornecer um serviço de formação de líderes, conforme descrição sintetizada abaixo.

\section{BIOLOGIA ALVO}

Pessoas que exercem, desejam ou necessitam exercer o papel de liderança, acima de 25 anos de idade, vindo de qualquer região do Brasil e que queiram se desenvolver na arte de estar com grupos ou responsável por um.

\section{IMPULSO}

A busca de uma melhoria na gestão, percebendo a necessidade de ampliar o relacionamento com a equipe e entre a equipe, o workshop servirá como uma base para iniciar a construção de relações mais saldáveis e mais eficazes para a equipe e seus trabalhos.

\section{PESADELO}

Estar à frente de um grupo e não saber como engajar os integrantes nos objetivos da empresa, apresentar alternativas de crescimento profissional e ainda construir um ambiente saudável

\section{INSATISFAÇÃO}

Não conseguir exercer liderança. 


\section{DESEJO}

Ser um excelente líder.

\section{FRUSTRAÇÃO}

Investimento em formações de liderança que não tragam resultado.

\section{SATISFAÇÃO}

Ser reconhecido pelos parâmetros da empresa como líder inspirador e transformador.

\section{VETOR}

O cliente vai acessar as divulgações do evento pelas redes sociais, também pelas divulgações nas empresas e associações parceiras.

\section{CANAL DE VALOR}

Empresas parceiras. $\mathrm{O}$ acesso via recursos humanos pode trazer mais segurança para quem busca o serviço, bem como potencializar o conhecimento do programa pelo público-alvo.

\section{RECOMPENSA}

Melhor desempenho profissional, ascensão profissional.

\subsection{Comparação das Ferramentas}

A leitura do conteúdo de cada quadrante das ferramentas, assim como está disposta neste artigo, torna os instrumentos confusos e um tanto ilegível como um planejamento estratégico de negócio, o que evidencia a necessidade da utilização dos quadros, para tornar a compreensão mais possível.

Também se faz necessário identificar a sequência de leitura dos quadrantes, assim como pede cada ferramenta, de forma a permitir melhor visão do negócio. 
Diante das aplicações realizadas, pareceu mais interessante que a ferramenta Brain Model Canvas seja a primeira a ser desenvolvida, pois ela dará uma ideia mais próxima de quem é seu potencial cliente, o que ele sente e deseja receber como produto ou serviço.

Após a visualização e (vamos chamar aqui de) conscientização do seu potencial cliente. Começamos a criação da tabela Business Model Canvas, que dará uma visão mais funcional de como seu negócio poderá funcionar num todo.

As duas ferramentas possuem uma lógica de construção, ambas tem por esboço os mesmos princípios, primeiro, ver você, ver suas ideias, seus sentimentos e sua proposta, depois, ver o cliente, saber o que ele precisa, o que ele necessita, o que ele quer, seguidamente vemos o valor que você tem a oferecer, que só pode ser mensurado olhando para você e o cliente, após isso vemos o mercado e vemos o funcionamento de todo o negócio.

Por fim, é importante usar as ferramentas sempre que necessite estruturar um negócio ou projeto. A essência e a vitalidade de seu negócio será você seu cliente e a relação que você estabelece com ele. As ferramentas serão úteis na visualização do todo.

Ambas as ferramentas possuem limitações quanto ao campo de visão do negócio, a ferramenta Business Model Canva foca muito na estrutura do negócio, tem um olhar menos amplo sobre o cliente e seus interesses. O Model Brain Canvas, no entanto, tem o foco quase que completamente sobre o cliente, sem estrutura do negócio. Para tal, ambas são necessárias e complementares.

\section{CONSIDERAÇÕES FINAIS}

Confusão, frustração, e conscientização, são as três palavras que melhor definem os sentimentos mais fortes vividos por mim no processo de criação deste artigo. A confusão iniciou-se por estar em um universo diferente dos quais estou acostumado, a forma de pensar diferente das minhas vivências enquanto profissional da psicologia. por não estar tão fluído, nisto, como achei que estaria antes de iniciar o desenvolvimento desta proposta. Foi para mim um processo penoso em questão de me comunicar sobre algo que ainda não sabia palpavelmente e não possuía as inclinações linguísticas da área (inclinações essas que ainda hoje não possuo). Por fim conscientização, pois hoje, tudo 
está mais fácil de compreender, a compreensão do funcionamento de minha proposta de negócio já não me é mais um enigma (mesmo considerando-me com pouco conhecimento)

Sendo assim, sinto que este conteúdo, muito bem orientado, é de grande valia para minhas aspirações. Tenho uma ideia mais clara do que quero, do que posso oferecer e de como fazer isto de uma forma mais eficaz.

No fim de tudo, as próprias ferramentas, vem de encontro com meu processo de vida e com a forma como trabalho. Uma busca constante em compreender o ser humano e permitir que, através de minha presença, ele possa se ver, com um novo olhar, e perceber em sí a capacidade humana que sempre está nele, mesmo que as vezes não enxergue. Portanto, técnicas, ferramentas ou métodos, vem para nos servir e assim devem-se ser tratadas.

\section{REFERÊNCIAS}

ANDION, M.C.; FAVA, R. Coleção Gestão Empresarial, academia.edu. 2002. Disponível em:

https://s3.amazonaws.com/academia.edu.documents/38118900/3.pdf?AWSAccessKeyId= AKIAIWOWYYGZ2 ${ }_{53} \mathrm{UL}_{3} \mathrm{~A} \&$ Expires=1549974359\& Signature=na\%2B9\%2F8Q a5oGMf 7mF\%2F\%2BLwR5FbOmU\%3D\&response-content-

disposition=inline\%3B\%2ofilename\%3DPlanejamento_Estrategico.pdf. Acesso em: 12/02/2019.

BEDÊ, Marco Aurélio. Sobrevivência das empresas no Brasil. Brasília: Sebrae, 2016.

BIAVA, Jônata de Oliveira. A metodologia Canvas e suas variações para o desenvolvimento do empreendedorismo. Universidade do extremo sul catarinense Unesc curso de administração de empresas. Criciúma 2017.

BRITO, Eriko; FURTADO, Felipe; Uma proposição Alternativa com as técnicas Business Model Canvas e Project Model Canvas para definição dos temas estratégicos e iniciativas 
Épicas do Portfolio backlog SAFe. XVI Seminário Nacional de Bibliotecas Universitárias. E II Seminário Internacional de Bibliotecas Digitais - Brasil. 2016.

BUENO, Jefferson Reis. O que é empreendedorismo. 2019. Disponível em: https://blog.sebrae-sc.com.br/o-que-e-empreendedorismo. Acesso em: 28/10/2019.

DICIONÁRIO FINANCEIRO. Business Model Canvas. Disponível em: https://www.dicionariofinanceiro.com/business-model-canvas/. Acesso: 29/10/2019.

ENDEAVOR. O que é Empreendedorismo: da inspiração à prática. Disponível em: https://endeavor.org.br/sem-categoria/o-que-e-empreendedorismo-da-inspiracao-apratica. Acesso em: 15/05/2020.

ENACHEV, Bruno Tsunashima. KAMINSKI Paulo Carlos. Introdução ao modelo de negócio: canvas. 2014. Disponível em: http://sites.poli.usp.br/p/paulo.kaminski/INTRODU\%C $3 \% 87 \% \mathrm{C}_{3} \% 83 \mathrm{O} \% 20 \mathrm{AO} \% 20 \mathrm{BU}$ SINESS\%20MODEL\%20CANVAS.pdf. Acesso em: 15/05/2020.

FONSECA, Araújo, FARIA Bruno. Cultura de Inovação: Conceitos e Modelos Teóricos. RAC, Rio de Janeiro, v. I8, n. 4, art. I, pp. 372-396, Jul./Ago. 2014.

MARCELO PERUZZO. Home Site. Disponível em: http://marceloperuzzo.com.br/. Acesso em: 29/10/2019.

SEITZ, Helgo Max. eGesta - Revista Eletrônica de Gestão de Negócios - Mestrado em Gestão de Negócios - Universidade Católica de Santos, 2005. 
STARTUPI. Alexander Osterwalder, criador do Business Model Canvas. Disponível em: https://startupi.com.br/201I/ı/video-com-osterwalder/. Acesso em 05/05/2020.

VIANNA, Mauricio, Design thinking: inovação em negócios, MJV Press, Rio de Janeiro, 2012. 